\title{
A facile route for graded conversion of carbon fabric to silicon carbide fabric and its oxidation kinetics study in atmospheric high-temperature environment
}

\author{
JYOTI PRAKASH ${ }^{1, *}$, MANASI GADE ${ }^{2}$, BHASKAR PAUL ${ }^{3}$ and KINSHUK DASGUPTA ${ }^{1}$ \\ ${ }^{1}$ Mechanical Metallurgy Division, Bhabha Atomic Research Centre, Trombay, Mumbai 400085, India \\ ${ }^{2}$ Department of Metallurgy and Materials Science, College of Engineering, Pune 411005, India \\ ${ }^{3}$ Materials Processing and Corrosion Engineering Division, Bhabha Atomic Research Centre, Trombay, Mumbai 400085, \\ India \\ *Author for correspondence (jprakash@barc.gov.in)
}

MS received 15 September 2017; accepted 18 December 2017; published online 27 July 2018

\begin{abstract}
Silicon carbide fabric converted from carbon fabric was prepared by a facile halide-activated pack cementation method. The XRD, SEM and EDS analyses confirm the formation of SiC fibres with graded conversion of carbon to $\mathrm{SiC}$ from surface to core of individual carbon fibres of carbon fabric. The graded conversion of carbon fibre to $\mathrm{SiC}$ was uniform and homogeneous throughout the fabric dimension. The thermokinetics of oxidation in atmospheric environment was studied by TGA analysis. The reaction kinetics and governing mechanism for oxidation of bare carbon fabric and silicon carbide fabric were calculated using Kissinger and Ozawa methods. It was observed that the activation energy for bare carbon fabric and silicon carbide fabric converted from carbon fabric are 62 and $174 \mathrm{~kJ} \mathrm{~mol}^{-1}$, respectively. Further, it was observed that the silicon carbide fabric converted from carbon fabric follows the second-order surface reaction oxidation mechanism.
\end{abstract}

Keywords. Carbides; vapour deposition; thermogravimetric analysis; surface properties.

\section{Introduction}

The materials for extreme applications, such as space aircraft [1], rocket shields [2] and braking systems [3] require high strength as well as thermal and oxidative resistances. Currently, high strength requirement is met by using carbon fibre-reinforced composites owing to their high aspect ratio and good strength [4]. It was observed that irrespective of type of carbon fibres, its rapid oxidation takes place at the operation temperature of above $673 \mathrm{~K}$ in oxidative environment [5], which makes it unsuitable even for oxidative low temperature atmospheric application. This limitation has given rise to modification of the composition in carbon fibre-based composites. To overcome this issue, two major ways with its own limitation are used, i.e., (i) impregnating carbon-fibre preform with ceramic matrix [6] and (ii) applying preventive layer coating on $\mathrm{C} / \mathrm{C}$ composite [7]. The other possible way is to coat/convert individual carbon fibres with protective layer before incorporating them into the composite [8-10]. The potential materials used for this purpose are silicon carbide (SiC) [5], boron carbide [11] and other materials [2]. There are few reports based on carbothermal reduction [12], precursor infiltration pyrolysis (PIP) [13], sol-gel [8] and chemical vapour deposition [14] methods on the protective layer coating of individual fibres before using them in composites. Ke-dong Xia et al [8] have reported silicon oxycarbide ceramic coating on carbon fibres using sol precursor. However, it was observed that debonding of coatings and surface cracks led to a reduction in tensile strength. Recently, Pillai et al [10] have reported deposition of crystalline silicon carbide on the carbon fibre substrate using plasma-enhanced chemical vapour deposition process. It was concluded that deposited coating was crystalline and the coating was uniform throughout the fibre tow. Further, dendrite growth was observed, which suggests non-homogeneity and rough surface. This implies that the deterioration occurs due to the collisions of the charged particles of plasma. Therefore, the challenges remain, i.e., homogeneous coating along the length of fibre, uniform coating on entangled carbon fibres in carbon-fibre preform, stability/performance of preventive layer coating in oxidative environment.

To address these issues, a facile method, i.e., halideactivated pack cementation (HAPC) was reported in the present work. In the present method, silicon metal was activated with ammonium fluoride to form active gaseous silicon fluoride intermediates. These diffuse through carbon-fibre substrate and convert carbon to silicon-carbide phase at hightemperature environment. The carbon fibres in loose form or in entangled carbon-fibre preform can be effectively converted to $\mathrm{SiC}$ uniformly throughout their length. There is graded conversion of carbon to $\mathrm{SiC}$ from top surface of carbon fibre to the core of carbon fibre. In addition, phase, 
microstructure and oxidation kinetics of such $\mathrm{SiC}$-converted carbon fibres were studied in detail.

\section{Materials and methods}

Carbon-fabric substrates (density: $0.90 \mathrm{~g} \mathrm{cc}^{-1}$ ) with the dimensions of $10 \mathrm{~mm} \times 10 \mathrm{~mm} \times 2 \mathrm{~mm}$ were prepared. The carbon fabric was prepared by weaving carbon fibres in desired pattern. The carbon fabric was porous in nature. The samples were ultrasonically cleaned with acetone and dried at $373 \mathrm{~K}$. The carbon fibres in carbon fabric were converted to $\mathrm{SiC}$ using HAPC method. The detailed pack cementation experimental procedure was reported earlier [15]. The HAPC experiment was carried out at temperature $1773 \mathrm{~K}$ for $10 \mathrm{~h}$. The pack comprising of $20 \mathrm{wt} \% \mathrm{Si}-2.5 \mathrm{wt} \% \mathrm{NH}_{4} \mathrm{~F}-77.5 \mathrm{wt} \%$ $\mathrm{Al}_{2} \mathrm{O}_{3}$ was used for this study. After the HAPC experiment, the specimens were cleaned under the water jet followed by ultrasonic cleaning and drying. The $\mathrm{SiC}$ fabric converted from carbon-fabric sample (termed as $\mathrm{SiC}$ fabric) was characterized for thickness, microstructure and composition using scanning electron microscopy (SEM)_Camscan MV2300CT/100, UK, equipped with energy dispersive spectroscopy (EDS) (Oxford, X-Max 80). The crystalline structures of SiC converted surface on carbon fibres were characterized by X-ray diffraction (XRD) - Philips Xpert pro XRD unit using CuK $\alpha$ radiation at an accelerating voltage of $40 \mathrm{kV}$, current of $35 \mathrm{~mA}$ and scanning rate of $0.05^{\circ} \mathrm{s}^{-1}$.

Non-isothermal oxidation tests were conducted at four heating rates of $5,8,12,15 \mathrm{~K} \mathrm{~min}^{-1}$ up to $1473 \mathrm{~K}$ for carbon fabric and $\mathrm{SiC}$ fabric using a thermogravimetric (TG) (Setsys Evolution, Setaram, France) equipment in static air environment. The weight changes of the specimens corresponding to oxidation were recorded continuously in TG mode.

The kinetics of solid-state oxidation reactions can be described by various equations taking into account the special features of their mechanism. In kinetic study of oxidation of carbon fabric and SiC fabric, Ozawa and Kissinger, Akahira and Sunose (KAS) equations were used to determine the activation energy $\left(E_{\alpha}\right)$ and pre-exponential factor $(A)$ of the oxidation reaction. These methods are well described and widely used in the literatures [16], which provide reliable results. Therefore, these methods are selected for kinetic analysis of the oxidation of the prepared composite. The equations used for $E_{\alpha}$ calculation are as follows:

Ozawa equation:

$$
\ln \beta=\ln \left(\frac{0.0048 A E_{\alpha}}{g(\alpha) R}\right)-1.0516\left(\frac{E_{\alpha}}{R T}\right) .
$$

KAS equation:

$$
\ln \left(\frac{\beta}{T^{2}}\right)=\ln \left(\frac{A R}{g(\alpha) E_{\alpha}}\right)-\left(\frac{E_{\alpha}}{R T}\right)
$$

$g(\alpha)$ is the integral form of $f(\alpha)$, which is the reaction model that depends on the reaction mechanism. According to the above-mentioned equations, the plots of $\ln \beta$ vs. 1000/T (equation (1)) and $\ln \left(\beta / T^{2}\right)$ vs. 1000/T (equation (2)) corresponding to different extents of conversion $\alpha$ can be obtained by a linear regression of the least-squares method. The activation energy $E_{\alpha}$ can be evaluated from the slopes of the straight lines with better linear correlation coefficients $\left(r^{2}\right)$, respectively. The activation energy values were calculated at the heating rates of 5, 7.5, 10 and $12.5 \mathrm{~K} \mathrm{~min}^{-1}$ via the mentioned methods in the $\alpha$ range of $0.03-0.32$. The mechanism function $g(\alpha)$ value was determined for most probable mechanism using the following equation [17]:

$$
\begin{aligned}
\ln g(\alpha) & =\left(\ln \left(\frac{A E_{\alpha}}{R}\right)+\ln \frac{e^{-x}}{x^{2}}+\ln h(x)\right)-\ln \beta ; \\
x & =\frac{E_{\alpha}}{R T}
\end{aligned}
$$

and

$$
h(x)=\frac{x^{4}+18 x^{3}+88 x^{2}+96 x}{x^{4}+20 x^{3}+120 x^{2}+240 x+120} .
$$

The plots of $\ln g(\alpha) v s . \ln \beta$ were carried out using a linear regression of the least-squares method. To determine the most probable mechanism function, the degrees of conversion $\alpha$ corresponding to four heating rates taken at the same temperature were substituted into the left side of equation (3) for all the 28 types of mechanism functions. If the mechanism functions according to equation (3) exhibit the slope and the linear correlation coefficient $r^{2}$ close to 1.0000 and unity, respectively, then the function $g(\alpha)$ is the most probable mechanism function.

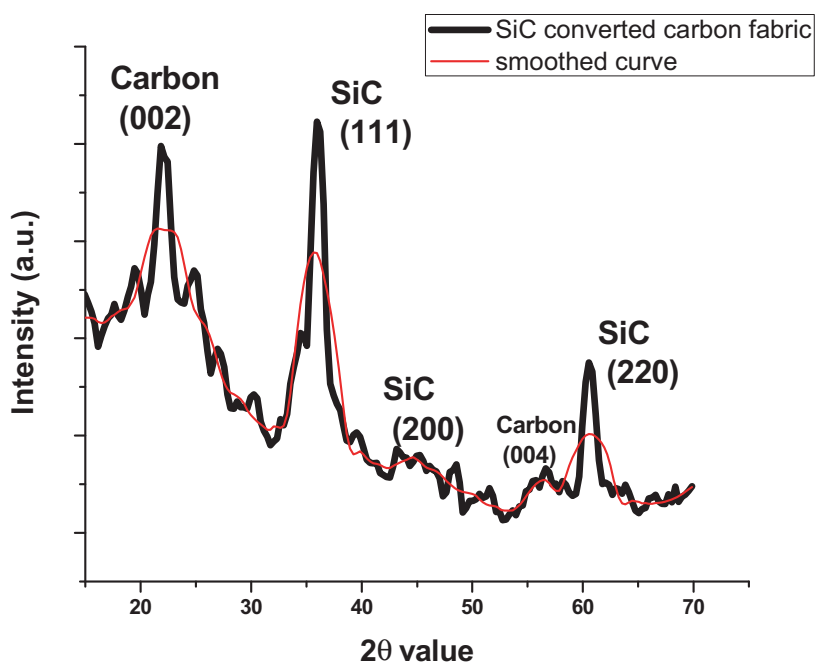

Figure 1. XRD pattern of the surface of as-prepared SiC fabric sample. 

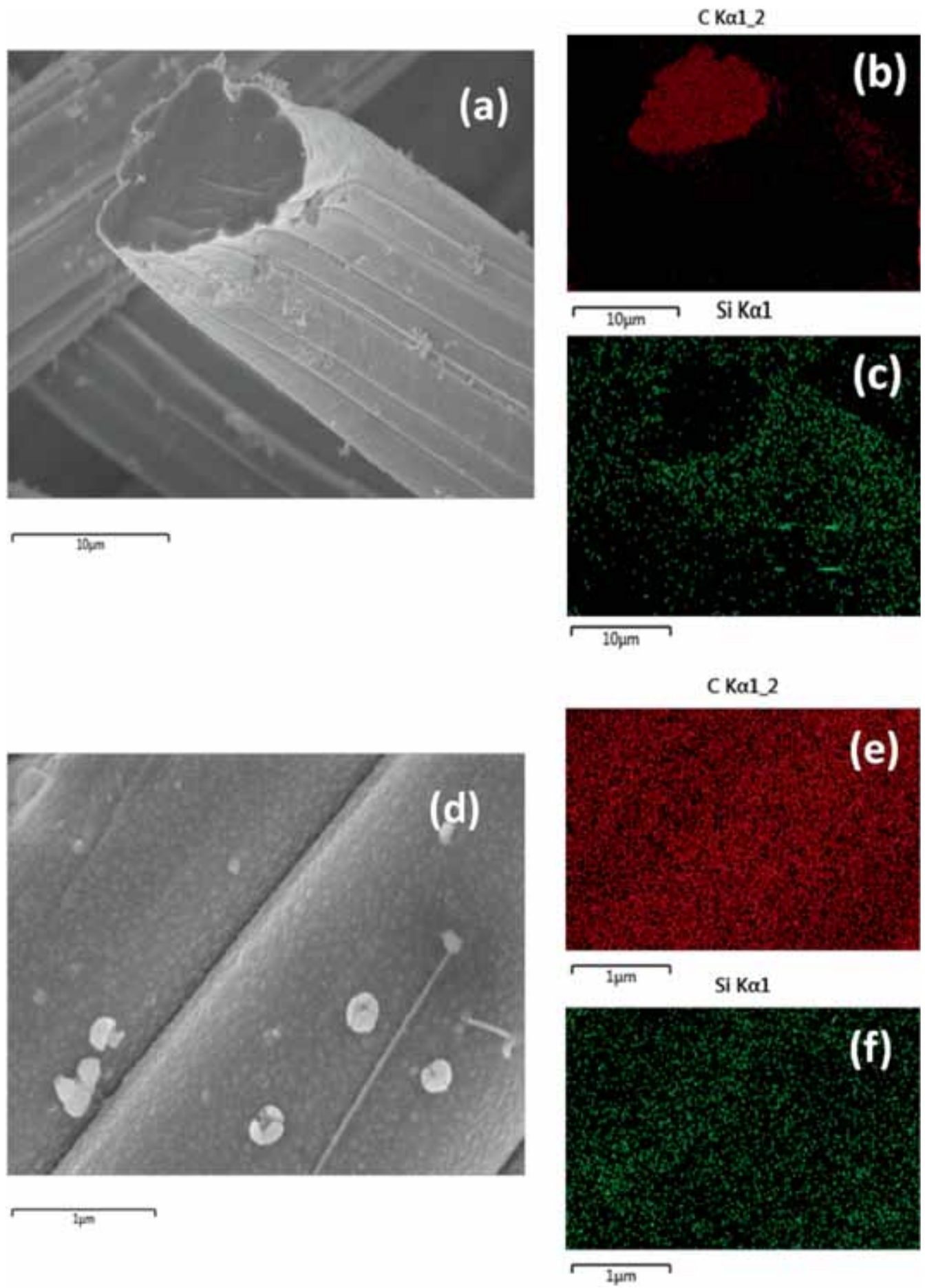

Figure 2. SEM images of the SiC fabric: (a) individual $\mathrm{SiC}$ fibre, (b and c) elemental mapping on the $\mathrm{SiC}$ fibre surface, (d) image of top surface of individual SiC fibre and (e and $\mathbf{f}$ ) elemental mapping on top surface of SiC fibre (red colour: carbon and green colour: silicon).

\section{Results and discussion}

The SiC fabric was prepared by HAPC method. One of the advantages of this method was that the $\mathrm{SiC}$ was formed uniformly on each surface of carbon fibres present in carbon fabric. This leads to the uniform and homogeneous conversion of carbon fibre surface to $\mathrm{SiC}$. The XRD profile of $\mathrm{SiC}$ fabric is shown in figure 1 . It was observed that there were distinguished diffraction peaks corresponding to carbon and crystalline cubical $\mathrm{SiC}$ phase in SiC-converted carbon fabric. The SEM micrograph (figure 2) of SiC fabric shows that each carbon fibre surface is homogeneously and 


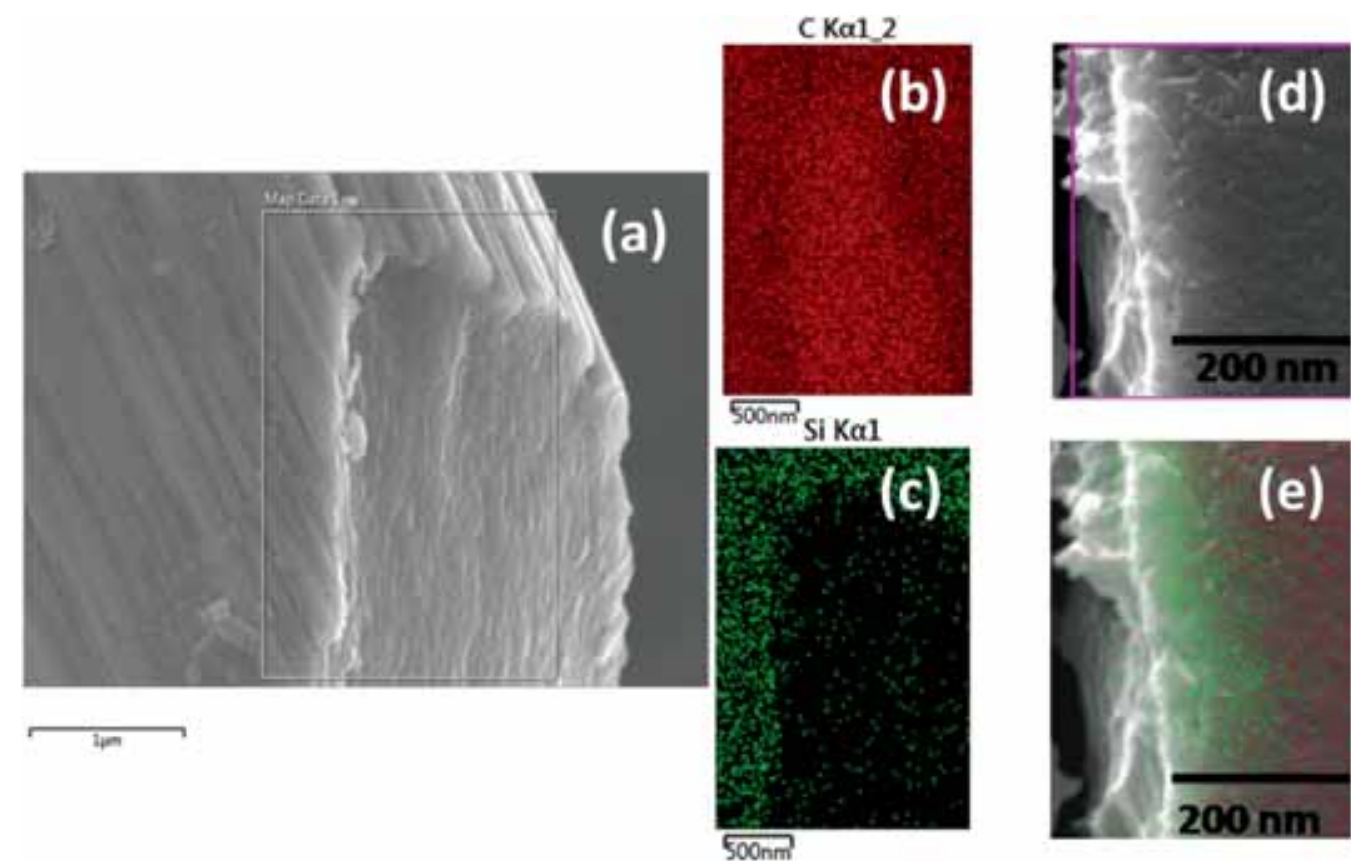

Figure 3. (a) Magnified SEM image of cross-section of individual SiC fibre, (b and c) elemental mapping on cross-section of $\mathrm{SiC}$ fibre, (d) magnified image of top surface in cross-section of individual SiC fibre and (e) elemental mapping on top surface in cross-section of individual $\mathrm{SiC}$ fibre (red colour: carbon and green colour: silicon).

uniformly converted to $\mathrm{SiC}$ along the length and the diameter. The cross-section images of individual $\mathrm{SiC}$ converted from carbon fibre (figure $3 \mathrm{a}-\mathrm{c}$ ) shows that there is gradient conversion of carbon to $\mathrm{SiC}$ when we move from the surface of carbon fibre to the core of carbon fibre. The top surface of carbon fibres are completely converted to $\mathrm{SiC}$ up to $100 \mathrm{~nm}$ (figure $3 \mathrm{~d}$ and e). It was reported that SiF2 [15] is the main gaseous constituent responsible for conversion of carbon to $\mathrm{SiC}$ in HAPC process. In HAPC process, the chemical potential gradient is the main driving force for diffusion of silicon fluoride vapours from the surroundings to the substrate surface in the pack. There are four major steps involved with the HAPC method, i.e., (i) gaseous reactive species (such as $\mathrm{SiF} 2$ ) formation; (ii) transportation of reactive species to the surface of substrate; (iii) dissociation of the silicon fluoride; (iv) absorption, diffusion and chemical reaction; and (v) desorption of gaseous by products. In the present case, absorption, diffusion and chemical reaction of $\mathrm{SiF} 2$ decide the degree of conversion of carbon from surface to core of carbon fibre. For the present duration of reaction, i.e., $10 \mathrm{~h}$ up to $200 \mathrm{~nm}$ of top carbon surface of carbon fibre completely converted to $\mathrm{SiC}$ phase and then, moving towards the core of carbon fibre, there is drastic decrease in $\mathrm{SiC}$ phase due to low diffusion of $\mathrm{SiF} 2$. The solid-state diffusion of vapour species, i.e., SiF2 from surface to bulk of carbon substrate limit the conversion rate. It was observed that with the partial conversion of carbon fibre to $\mathrm{SiC}$, the flexibility of carbon fibre remains same in comparison with the coated carbon fibre. Normally, the CVD-coated carbon fibres tend to get stiff due to extra layer formation over the carbon fibre surface. This can hamper the further processing of fibre to composite. But in the present case, the processing of $\mathrm{SiC}$ fabric can be easily done to make composites of desired characteristics.

The thermogravimetric analysis (TGA) and differentialTGA curves of carbon fabric and $\mathrm{SiC}$ fabric are shown in figure $4 \mathrm{a}$ and $\mathrm{b}$, respectively. From TGA curves (figure 4a, table 1), it was observed that the oxidation process of carbon fabric began from $865 \mathrm{~K}$, but that of $\mathrm{SiC}$ fabric started from $1008 \mathrm{~K}$. The carbon fabric was burnt at $1029 \mathrm{~K}$ and $23-24 \%$ weight of $\mathrm{SiC}$ fabric was retained at $1164 \mathrm{~K}$. From TGA curves (figure 4a), it was observed that the oxidation of $\mathrm{SiC}$ began from $1164 \mathrm{~K}$ and weight gain was observed in the TGA curve. The weight gain indicated the formation of $\mathrm{SiO}_{2}$ layer over the $\mathrm{SiC}$ surface due to the oxidation of the exposed $\mathrm{SiC}$ surface. From differential-TGA curve (figure $4 b$ ), it was observed that the oxidation reaction rate $(\mathrm{d} a / \mathrm{d} T)$ of $\mathrm{SiC}$ fabric was maximum when it was burnt off $33 \%$. It was observed from differential-TGA that there are two peaks at 1060 and $1107 \mathrm{~K}$. At the first peak temperature of $1060 \mathrm{~K}$, oxidation of carbon from fibre occur due to the diffusion of oxygen through micropores/cracks generated on surface at high temperature. At this point, the surface reaction rate is exceeded when compared to diffusion rate of oxygen gas due to the availability of more active sites. Hence, overall reaction should be controlled by gas diffusion. But the generation of second peak around $1107 \mathrm{~K}$ indicated that the diffusion control reaction was not the rate-limiting step. The second peak at $1107 \mathrm{~K}$ 
can be attributed to the competitive oxidation of carbon and silicon carbides. The oxidation of $\mathrm{SiC}$ leads to the formation of inert silica layer, which reduces the number of active carbon sites. So, the oxidation rate reduces and gas diffusion rate exceeds with respect to surface reaction. In this scenario, the overall oxidation reaction of $\mathrm{SiC}$ fabric could be controlled by the chemical reaction.

To determine the oxidation kinetics of $\mathrm{SiC}$ fabric sample, well known KAS and Ozawa methods were used. The

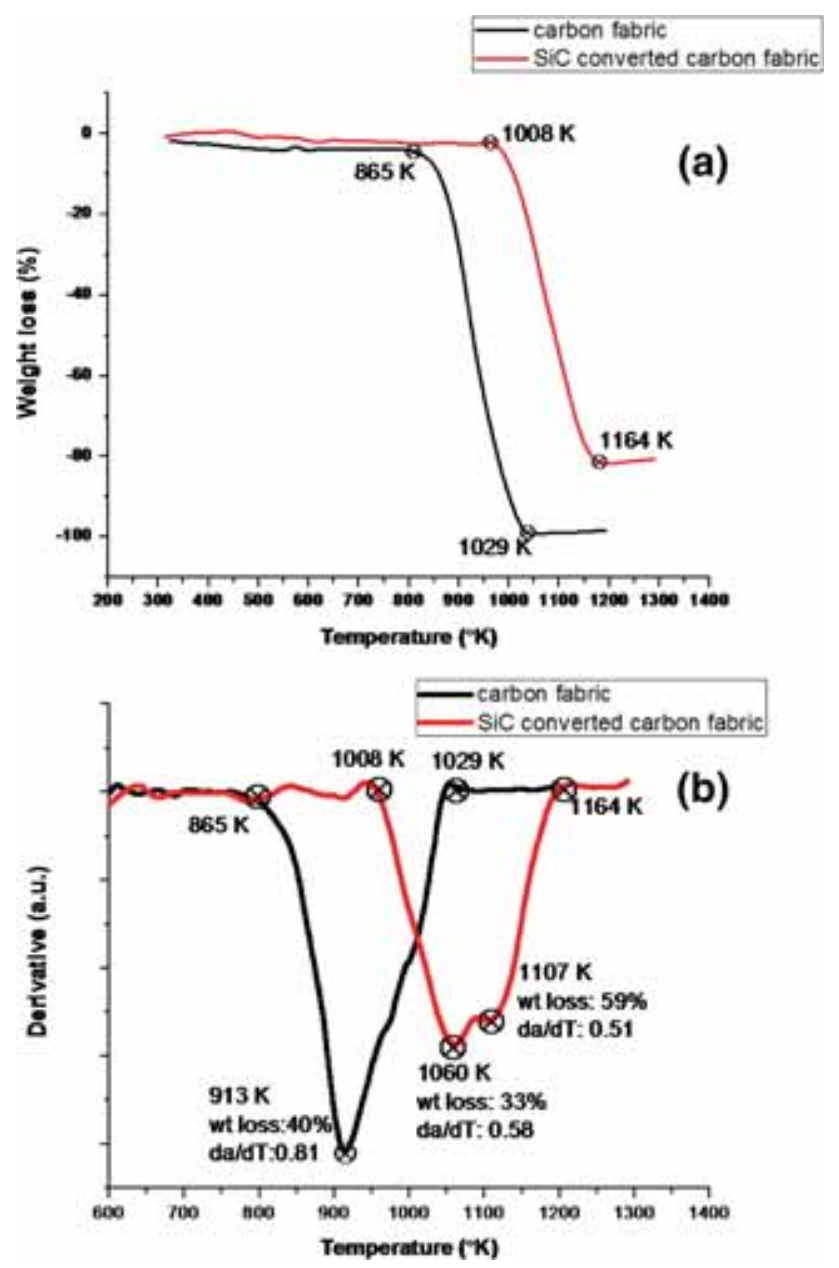

Figure 4. (a) Thermogravimetric and (b) derivative analyses of bare carbon fabric and $\mathrm{SiC}$ fabric in atmospheric environment. calculated results from Ozawa and KAS methods according to four TG measurements are presented in table 2.

The average activation energy values of $\mathrm{SiC}$ fabric calculated from Ozawa and KAS methods are 184 and $164 \mathrm{kJmol}^{-1}$, respectively. Further, average activation energy values of bare carbon fabric calculated from Ozawa and KAS methods are 64 and $59 \mathrm{~kJ} \mathrm{~mol}^{-1}$, respectively. The activation energy of the oxidation is reliable via the small difference of the calculated values from the two methods $\left(\sim 20 \mathrm{~kJ} \mathrm{~mol}^{-1}\right)$. The results of the most probable mechanism functions during the oxidation process are tabulated in table 2 . The calculated mechanism function shows that the oxidation of $\mathrm{SiC}$ fabric follow 3D diffusion (Zhuravlev-LesokhinTempel'man-ZLT model) below the reaction temperature of $1060 \mathrm{~K}$ and follows second-order reaction mechanism at the reaction temperature of $1107 \mathrm{~K}$ and above. Therefore, it can be stated that the mechanism function with differential form $f(\alpha)=1.5(1-a) 4 / 3[(1-a)-1 / 3-1]-1$ and integral form $g(\alpha)=[(1-a)-1 / 3-1] 2$ belong to the mechanism of $3 \mathrm{D}$ diffusion reaction following the ZLT equation below the reaction temperature of $1060 \mathrm{~K}$. In the similar way, mechanism function with differential form $f(\alpha)=2(1-a) 3 / 2$ and integral form $g(\alpha)=[1-(1-a) 2]$ belong to the mechanism of second-order reaction at and above reaction temperature of $1107 \mathrm{~K}$. This is in consent with our oxidation results, i.e., presence of two troughs as shown in figure 4b. Presence of two troughs in differential TGA curve represents two kinds of oxidation reactions. In the present case of oxidation of $\mathrm{SiC}$ fabric, oxidative gas can diffuse from the exposed surface due to the micropores/cracks generated on the surface at high temperature oxidative environment. If one looks at the possibility of different steps in oxidation process, it was observed that in the first step, carbon exposed due to formation of pores/cracks on the surface of individual fibre of $\mathrm{SiC}$ fabric, initially gets oxidized. This initiation of oxidation process leads to the formation of more active carbon sites. So, the diffusion is rate-limiting step. Whereas in the second step, the diffusion of oxygen through these micro cracks/pores to carbon active sites inside carbon fibre is limited due to healing of micropores/cracks. The reaction of reactant oxygen, carbon and $\mathrm{SiC}$ will lead to the formation of products (such as silica, $\mathrm{CO}, \mathrm{CO}_{2}$, etc.) and the diffusion of the products out of the system. Thus, the second trough represents the

Table 1. The values derived from TG curve of the oxidation of bare carbon fabric and SiC fabric in static air atmosphere.

\begin{tabular}{lcccc}
\hline Environment & Sample & Onset temperature (K) & $\begin{array}{l}\text { Temperature at which } \\
\text { different weight losses (\%) } \\
\text { occurred (K) }\end{array}$ & $\begin{array}{l}\text { Residual yield (\%) } \\
\text { (particular temperature) }\end{array}$ \\
\hline Static atmospheric condition & Bare carbon fabric & 865 & $900(29 \%)$ & $0(1040 \mathrm{~K})$ \\
& SiC fabric & 1008 & $1037(15 \%)$ & $23-24 \%(1164 \mathrm{~K})$ \\
\hline
\end{tabular}


Table 2. Results of activation energy and most probable mechanism functions during the oxidation process.

\begin{tabular}{lccc}
\hline Sample & Activation energy (kJ mol $\left.{ }^{-1}\right)$ & Temperature (K) & Reaction mechanism \\
\hline Carbon fabric & 64 (Ozawa), 59 (KAS) & $865-1040$ & 3D diffusion (anti-Zhuravlev-Lesokhin-Tempel'man model) \\
SiC fabric & 184 (Ozawa), 164 (KAS) & $1008-1060$ & 3D diffusion (Zhuravlev-Lesokhin-Tempel'man model) \\
& & $1107-1211$ & Second-order reaction mechanism \\
\hline
\end{tabular}

competitive oxidation of carbon and $\mathrm{SiC}$. Due to non-availability of active carbon surface, the reaction mechanism is governed by the surface reaction. Further temperature increase after $1164 \mathrm{~K}$ leads to weight gain, it represents oxidation of $\mathrm{SiC}$ and formation of silica phase. The formation of silica phase leads to the complete healing of pores/microcracks and further prevents the oxidation of the carbon fibre.

\section{Conclusion}

The SiC fabric was prepared from carbon fabric using facile and simple HAPC method. The graded conversion of carbon fibres to $\mathrm{SiC}$ in carbon fabric was carried out uniformly and homogeneously throughout the length of the fibre. Even, bent area of carbon fibres in carbon fabric was also converted to $\mathrm{SiC}$ effectively. In comparison to CVD/PIP/sol-gel methods, the present reported method has shown better uniformity in conversion of carbon fibre to $\mathrm{SiC}$. Such graded conversion of carbon fabric to $\mathrm{SiC}$ leads to the enhancement of oxidative performance in static air environment. Use of such $\mathrm{SiC}$ fabric in place of simple carbon fabric in preparation of advance composite will lead to the extraordinary performance of composites in extreme environment. Further, such study of oxidation mechanism is essential to simulate and design a good oxidation-resistant high strength composite for commercial applications.

\section{References}

[1] Hopkins A R, Labatete-Goeppinger A C, Kim H and Katzman H A 2016 Carbon 10777

[2] Tang S and Hu C 2017 J. Mater. Sci. Tech. 33117

[3] Wu S, Yi M, Ge Y, Ran L and Peng K 2017 Carbon 117 279

[4] Li Y, Cai S and Huang X 2017 Compos. Sci. Tech. 14389

[5] Prakash J, Venugopalan R, Paul B, Bahadur J, Ghosh S K and Sathiyamoorthy D 2013 Corros. Sci. 67142

[6] Tai N and Chen C 2001 J. Am. Ceram. Soc. 841683

[7] Smeacetto F, Salvo M and Ferraris M 2002 Carbon 40 583

[8] Xia K, Lu C and Yang Y 2015 New Carbon Mater. 30236

[9] Yuanjian T, Xiaoqian W, Hua S and Lianghua X 2011 Corros. Sci. 532484

[10] Pillai R, Batra N, Manocha L M and Machinewala N 2017 Surf. Interfaces 7113

[11] Das M, Ghosh J and Basu A K 2010 Ceram. Int. 362511

[12] Das M, Basu A K and Ghatak S 2009 J. Eur. Ceram. Soc. 29 2129

[13] Tong D, Wang H, Wang L, Chen L and Li Z 2017 Surf. Coat. Technol. 319335

[14] Li J S, Zhang C R and Li B 2011 Appl. Surf. Sci. 2577752

[15] Paul B, Prakash J and Sarkar P S 2015 Surf. Coat. Technol. 282 61

[16] Vlaev L, Nedelchev N, Gyurova K and Zagorcheva M 2008 J. Anal. Appl. Pyrol. 81253

[17] Pérez-Maqueda L A and Criado J M 2000 J. Thermal Anal. Cal. 60909 